\title{
Characterization of historic bricks and binder at Vat Phou World Heritage Site in Lao PDR and selection of compatible replacement units for restoration
}

\author{
Swathy Manohar*, Shivangi Shukla, Arun Menon and Manu Santhanam \\ Department of Civil Engineering, Indian Institute of Technology Madras, Chennai 600 036, India
}

This article presents results of material characterization studies conducted on historical clay bricks and binder sampled from the brick masonry gallery of the southern quadrangle of the World Heritage Site of Vat Phou in Champasak, Province of Lao PDR. The primary objective of the sampling was to conduct micro-analytical laboratory studies on the binder in the brick masonry to establish the nature of the binding mortar used and to verify the presence of lime in it, if any. In addition, micro-analytical and physicomechanical tests conducted on the historic brick samples were used to establish compatibility with the newly manufactured replacement bricks for use in the restoration of the dilapidated brick gallery. X-ray diffraction technique was used to study the mineral composition in the system, and scanning electron microscopy provided images indicative of the material and binder characteristics. The study revealed that lime was not present in the binding mortar and it could possibly be a natural wood resin. The use of natural resins as a binder in masonry has been a popular theory in Southeast Asia, and these results provide first empirical proof of their use. This study also demonstrates how compatibility checks can be carried out between historic and new replacement bricks through analysis of their pore structure and physical properties. In addition, the test results established that lime was not a component of the ancient binder, which together with the evidence of the resinbased binder provides an important direction for restoration efforts of historical sites in the Mekong River Basin region covering countries such as Lao PDR, Cambodia and Vietnam.

Keywords: Binder, heritage conservation, historic bricks, restoration efforts.

VAT PhOU is a UNESCO World Heritage Site, a Khmer Hindu temple complex located in southern Laos, at the base of Mount Phou Khao. Though the original temple at the site was built in the early 5th century, current

*For correspondence. (e-mail: swathymanohar@yahoo.com) elements in the vast complex are reported to be constructed during the 11 th-13th century, and are now in a partially dilapidated condition ${ }^{1}$. The temple complex has different structures made of various materials like laterite, sandstone, clay bricks, etc. major among them being the sanctuary, northern quadrangle and southern quadrangle. Figure 1 shows the plan of monuments in the Vat Phou site ${ }^{2}$ and a panoramic view of the site. Various parts of the heritage site are undergoing extensive restoration for the past two decades ${ }^{3-5}$. The southern quadrangle marked with a rectangle at the bottom right corner in Figure $1 a$ is the focus of the present study.

Ensuring efficient and optimized restoration protocols from a scientific perspective of understanding the materials are necessary in the field of built heritage conservation $^{6,7}$. The International Council of Monuments and Sites (ICOMOS) has specified in its guidelines on conservation practices that information on the structure in its earlier and current state, construction techniques used, repairs in the past and the phenomena (deterioration mechanisms) that the material underwent shall be inferred in detail ${ }^{8}$. Compatibility between new and old materials is a key factor to consider during restoration works in line with internationally accepted principles of guaranteeing that the values of authenticity and historicity are not compromised. In this regard, ICOMOS suggests 'the choice between traditional and innovative techniques should be weighed up on a case-by-case basis and preference given to those that are least invasive and most compatible with heritage values, bearing in mind safety and durability requirements ${ }^{\prime}$. The International Scientific Committee on the Analysis and Restoration of Structures of Architectural Heritage (ISCARSAH), which is an international scientific committee founded by ICOMOS, has also specified the significance of compatibility between traditional/original materials and new materials in conservation. Compatibility shall be ensured with respect to masonry units and binders. It is mentioned that the choice of fluid mortars, which include resins, lime, cement, etc. for injection into the existing masonry for repair works, should depend upon the characteristics of existing materials in 


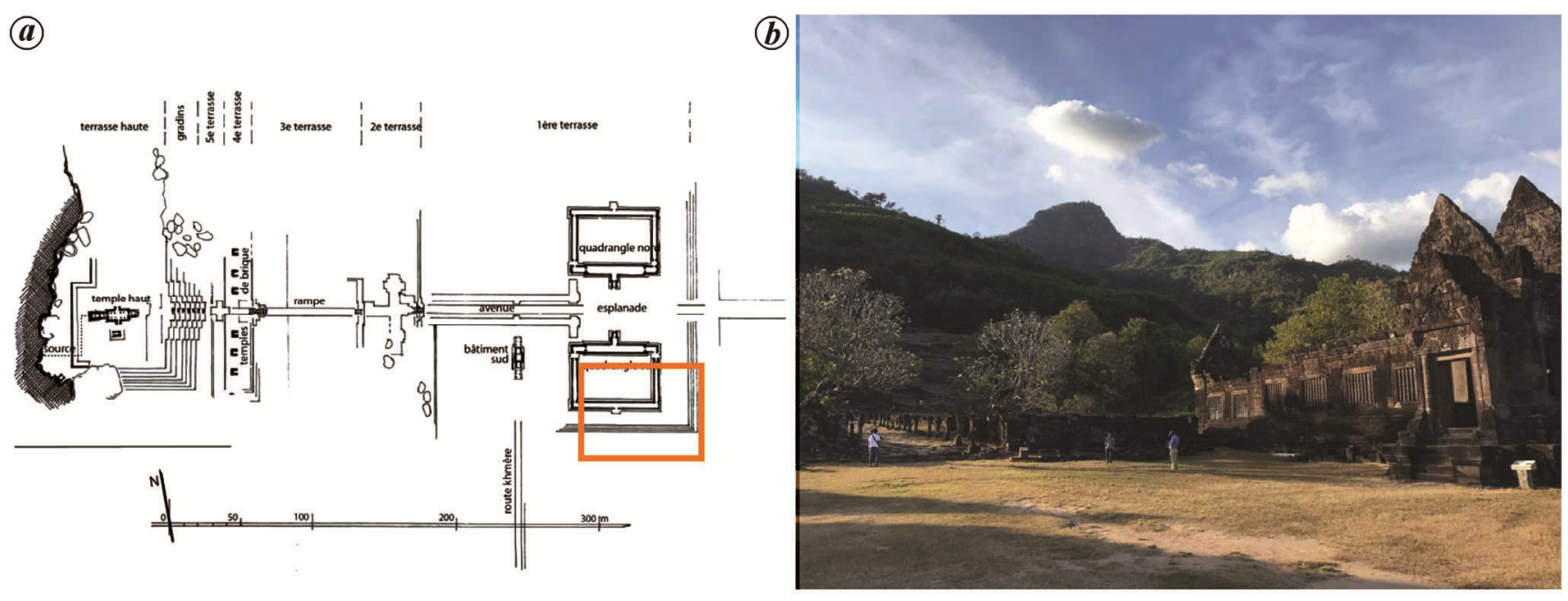

Figure 1. $\boldsymbol{a}$, Plan of monuments at Vat Phou heritage site $^{2}$, Laos. $\boldsymbol{b}$, Panoramic view showing Mt. Phou Khao, the northern quadrangle and the avenue.

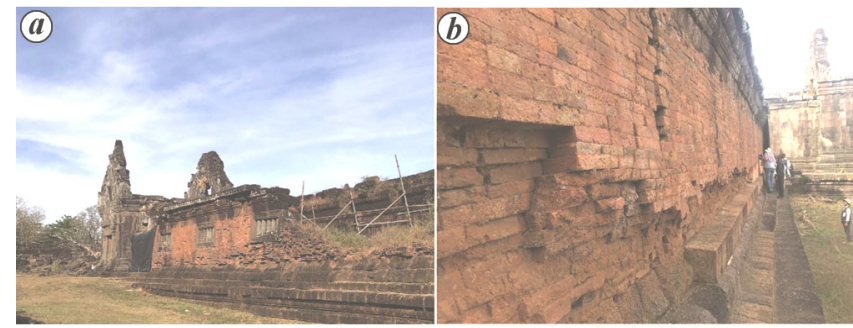

Figure $2 \boldsymbol{a}, \boldsymbol{b}$. Images showing the extent of damage due to differential settlement at the brick gallery in the southern quadrangle.

the historic structure ${ }^{9}$. The characteristics of the materials, both at macro and microstructural levels, can indicate specifics about the origin of a material and the expected durability performance ${ }^{10,11}$. The present study discusses the approach adopted during the investigative phase for restoration works at the western brick masonry gallery of the southern quadrangle of the Vat Phou temple complex. Figure 2 shows the brick gallery at the southern quadrangle. Characterization of ancient bricks and the binder used was done, which could guide in strategies for identifying compatible new materials to be used. The rest of the structure is constructed predominantly in laterite and sandstone. The Archaeological Survey of India, Government of India is in charge of conserving this World Heritage Site.

\section{Materials and methods}

\section{Samples}

One sample of brick masonry composed of two historic clay brick units bonded to each other extracted from the brick masonry gallery of the southern quadrangle of the Vat Phou World Heritage Site was used as the historic sample. Two samples of newly manufactured clay brick masonry units of dimensions customized to match the historic bricks, reportedly sourced from Vietnam, were the replacement samples tested for compatibility with the historic bricks.

\section{Physico-mechanical tests}

Compressive strength was measured flat-wise according to IS 3945 (Part 1): 1992 for the bricks at a loading rate of $140 \mathrm{~kg} / \mathrm{cm}^{2} / \mathrm{min}$. Efflorescence test was conducted according to IS 3495 (Part 3): 1992, which measures the liability of the material to efflorescence (external salt precipitation as white patches). The test primarily identifies the presence and type of efflorescence in the brick on exposure to water for seven days. The bricks were partially immersed ( $25 \mathrm{~mm}$ height) in water for capillary suction. Water absorption was measured according to IS 3495 (Part 2): 1992, in which the percentage mass of water absorbed to the mass of dry brick is calculated after $24 \mathrm{~h}$ of complete immersion of oven-dry bricks in water.

\section{Micro-analytical tests}

Mineral composition of the heritage brick samples was explored using X-ray diffraction (XRD). The method identifies crystallographic and mineralogical characteristics of a material from the interaction of X-rays (from an external source) and atoms in the material. The output is an X-ray pattern called the diffractogram, which shows distinct peaks for various crystalline phases in the material. The preparation of samples for XRD involved crushing, powdering and sieving the representative material through a $75 \mu \mathrm{m}$ sieve. Patterns were obtained by step scanning from $5^{\circ}$ to $90^{\circ} 2 \theta$ with a count of $0.5 \mathrm{sec} / \mathrm{step}$. 


\section{RESEARCH ARTICLES}

The peaks were identified using X'PERT HighScore software.

Scanning electron microscopy (SEM) is an advanced microscopic imaging tool to characterize materials at the microscopic level that works by scanning the sample with an energetic electron beam focused with electromagnetic lenses. SEM can be used at very high magnification, to even bring to light features at the nano-scale and has a large depth of field when compared with optical microscopes. In the present study, secondary electron imaging was used to determine the morphological characteristics of the bricks - at the core and the joining interface between two bricks.

Mercury intrusion porosimetry (MIP) was used to study and compare the pore parameters of the existing and newly manufactured bricks. Parameters such as size of pores, their distribution and volume proportion, shape of pores and their interconnections affect the physical properties of bricks and stones. They are considered as the most critical details to be studied for understanding durability of a fired clay brick. Pores or fissures are the in-built natural pathways in a material through which water or other fluids enter and flow through, thus facilitating physical, chemical and biological weathering. Fluid storage and circulation potential, salt crystallization and freeze-thaw cycles in the building materials are issues directly related to open pores. Hence, the pore properties and their interconnections were found to have a direct influence on the deterioration rates in the masonry units $^{11}$. MIP measures the amount of mercury intruded under incremental pressures. Since the pressure is inversely proportional to pore size, the pore structure features can thus be obtained from this experiment. A 140 $440 \mathrm{~Pa}$ porosimeter instrument (Thermo Scientific) was used to measure the total porosity and pore parameters of the historic and new brick samples. Samples weighing about $0.5-0.8 \mathrm{~g}$ were collected from each brick and broken into 3-4 small pieces to maximize the exposed surface area for facilitating mercury intrusion.

\section{Results and discussion}

The results are presented in three categories depending upon the features addressed in the study. We have examined the characteristics of the heritage bricks used at the Southern quadrangle of the Vat Phou site, followed by studying the type and nature of the binder used, if any, and testing the compatibility of the heritage bricks with a set of newly made bricks to predict whether they can be used effectively for restoration works.

\section{Characteristics of the historical bricks}

Visual observations: The external surfaces of the heritage brick units collected from the site were uneven, partly eroded and non-uniformly black in colour due to the presence of atmospheric and biological depositions (Figure 3). The internal (unexposed to the external environment) surfaces were reddish-orange in colour. From the cut cross-section, it was observed that the internal core of each of the bricks had a deep black colour, which

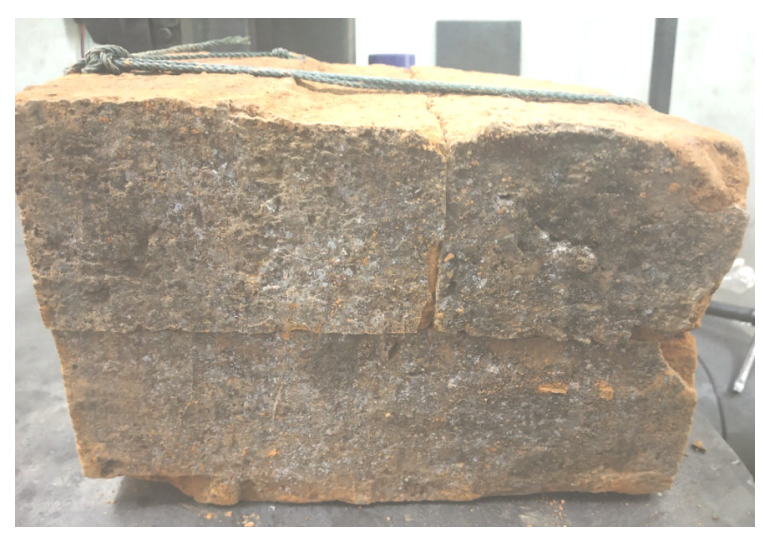

Figure 3. Historic bricks masonry prism with two bricks bonded together.

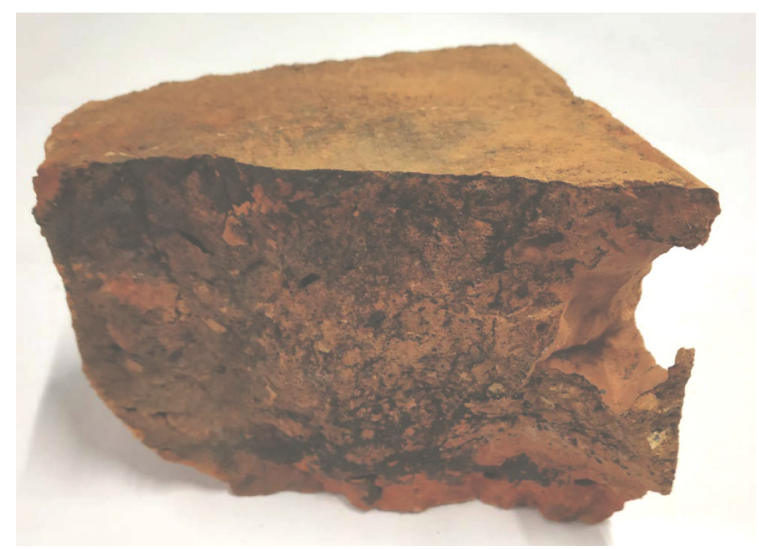

Figure 4. View of the cross-section of a historic brick showing the presence of soot.

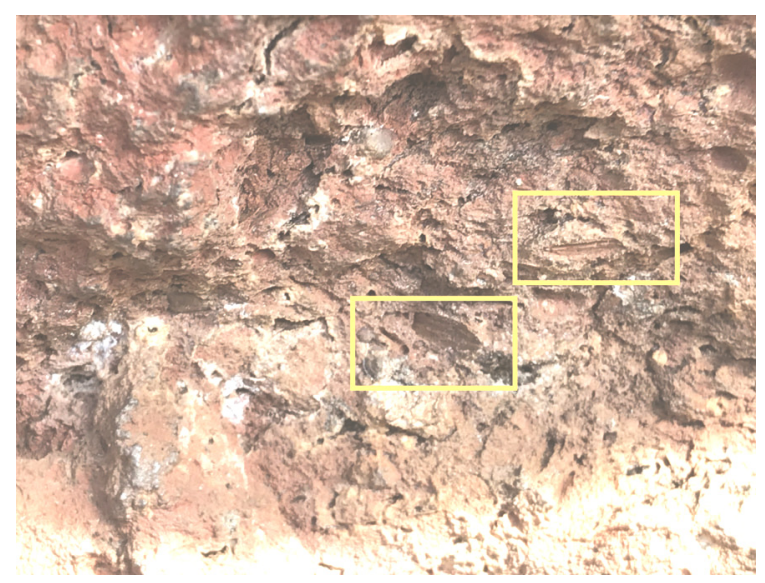

Figure 5. Surface of the brick unit showing the presence of inclusions, possibly rice husk. 

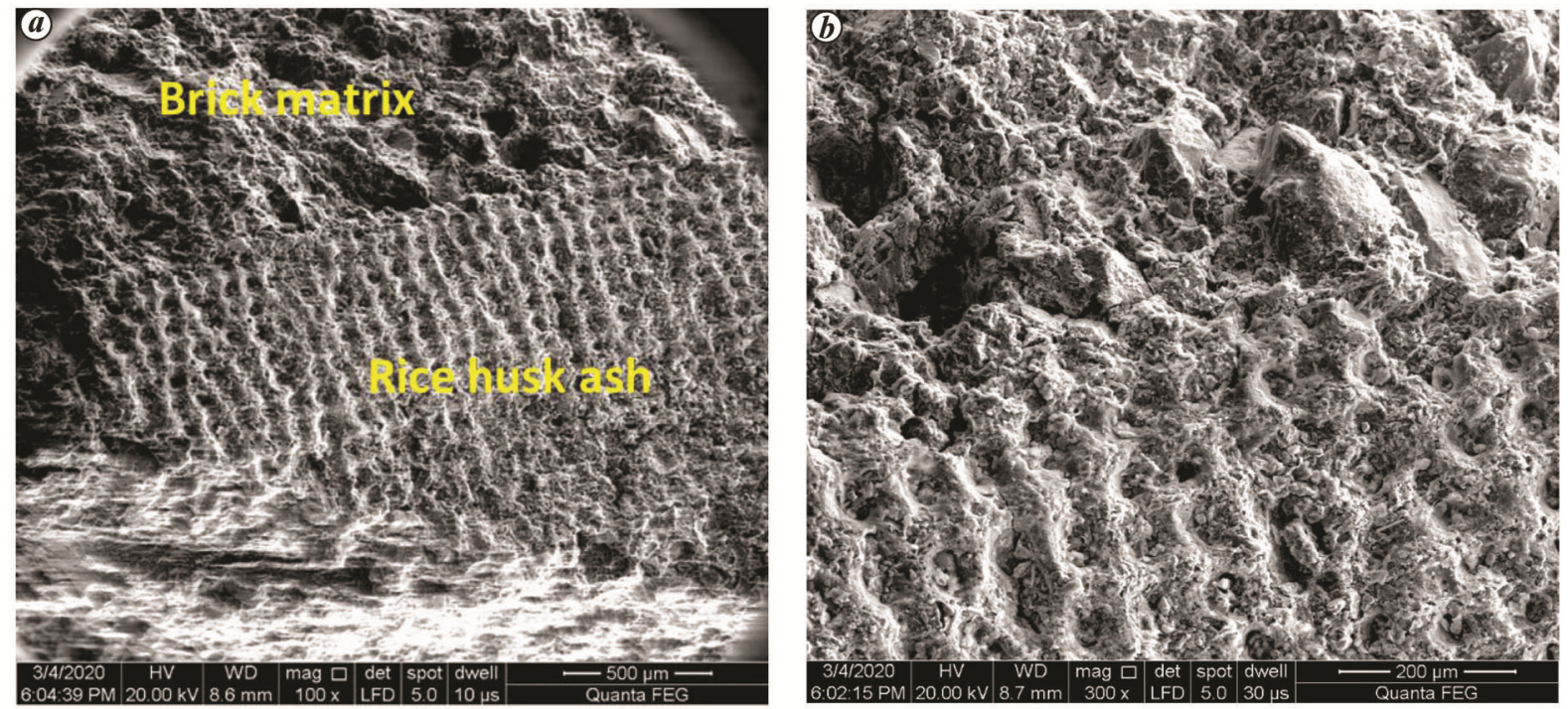

Figure 6. $\boldsymbol{a}$, Scanning electron microscope image of the core of a historic brick sample. $\boldsymbol{b}$, Magnified view of the image in Figure $6 a$ showing vesicular morphology of rice husk ash.

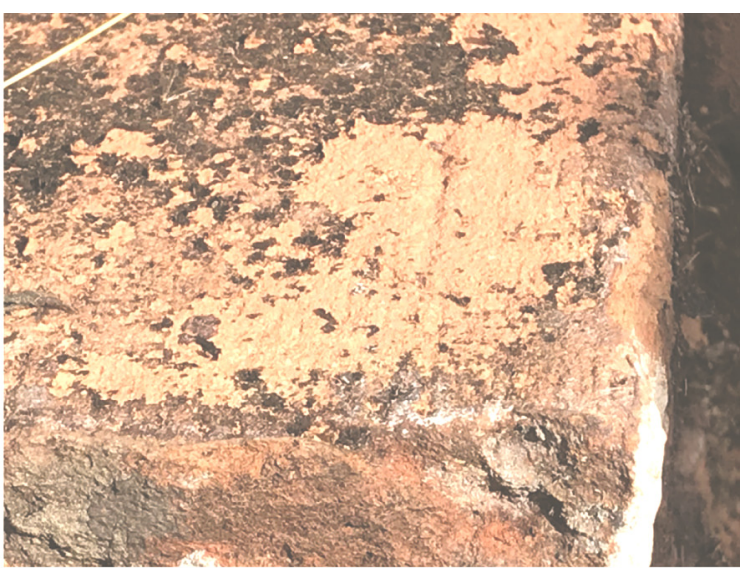

Figure 7. Bonded surface of a brick showing the presence of an interfacial layer between bricks.

represents soot (Figure 4). The soot was observed as a deep black powdery layer, generally of amorphous carbon. This suggested the incomplete burning of organic matter. Impressions of rice husk were seen on the surface of the bricks, from the masonry at the site (Figure 5). Fibrous inclusions were also observed in the core of the brick matrix similar to the masonry surface, more obvious in the reddish-orange areas - possibly rice husk, whose presence was then analysed through SEM imaging. Addition of raw rice husk or grounded rice husk ash into the clay during brick manufacturing was practised in ancient times, particularly in the rice cultivation areas, such as the Mekong delta region; rice husk stabilizes the clay and improves shrinkage properties.

Morphological observations: SEM images were taken using samples prepared from the core of the historic brick sample. Figure $6 a$ and $b$ shows the SEM image of the brick sample taken from the core. Rice husk was detected in the brick matrix; it was composed of quartz and feldspar in abundance. The highly siliceous rice husk ash was identified with its highly porous and vesicular morphology, which results in a very high external surface area. Figure $6 b$ shows magnified images of rice husk. In all probability, it was raw rice husk and not rice husk ash, that was added to the plastic clay during the brick manufacturing process to improve the shrinkage properties. Rice husk impressions seen in the reddish-orange portions of the brick support this conjecture, as seen in Figure 3. They also contribute to non-uniform burning during the firing process that was seen as soot in the core. On the other hand, rice husk ash is much finer and has pozzolanic properties, resulting in a lesser negative impact on strength than raw rice husk.

\section{Identification of the binder characteristics}

We examined in detail the properties at the interface, or more precisely, the bed and head joints between individual brick units; whether a binder existed between the bricks, and if so, the nature of the binder.

Visual observations: Figure 7 provides visual evidence of the existence of possibly an interfacial layer between the bricks from the site. Reports from the conservation studies conducted at other sites in the vicinity have revealed different inferences. Studies conducted on the brick masonry from temples at the archaeological site of Mỹ Sơn, Vietnam, showed the presence of very thin layers of natural resin that made the bond tight, so that there were practically no real joints between the bricks ${ }^{12}$. 


\section{RESEARCH ARTICLES}

However, a peculiar characteristic of some of the brick masonry at Phnom Bakheng Brick Shrine was the absence of any kind of binder ${ }^{13}$. Tests conducted suggested the possibility of rubbing and fixing the bricks with friction effects in the presence of moisture.

Mineralogical identification: Samples were collected from the core of the historic brick and the interface where both the bricks were joined. XRD helps identify any possible differences between the interior (core) of the bricks and the interface between two bricks, which can possibly provide evidence on the binder used. Figure 8 compares diffractograms for the samples collected from the core of the bricks (bottom graph) and the interface (top graph). The major minerals found in both the samples were quartz, feldspar, diopside and gehlenite.

We also examined the presence of lime in the system, if any. This was done because of the standard conservation practice in recent times at historic sites to use lime as a binder during repairs. Confirmation on the presence or absence of lime can influence the choice of new materials during the restoration works. Even though the first peak of lime (at $2 \theta=37.62^{\circ}$ ) matched with a peak in the measured profile of the brick system in both cases, the absence of other relevant peaks eliminated the chance of lime being in the system. This clearly indicates that lime was not used as a binder in the system. Also, the similar nature of mineral composition identified between the core and the joining interface suggests that the binder used can be either organic without any crystalline phases, or no binders were used at all. Further analysis at the interface with SEM was necessary to confirm this.

Morphological features at the joining interface in the historic bricks: Figure 9 shows the SEM image taken for a sample collected from the interface. The joined surface of the brick was examined by capturing secondary electron images. Clear evidence for the presence of a coating/layer could be seen on the surface in the SEM image, which was not possible with the naked eye. This film suggests the presence of a very thin layer of binder, probably non-crystalline in nature, in corroboration with the XRD results. The bright lines in Figure 10 show cracks within the film, where electron deposition would have occurred due to the discontinuity, which resulted in enhanced brightness in such locations in the SEM images.

A report on the study of bricks used in the Phnom Bakheng temple, which is also a Khmer Hindu temple at Angkor, Cambodia (about $400 \mathrm{~km}$ away from Champasak, Laos) in 2010 by the World Monuments Fund (WMF), showed significant similarity to those at Vat Phou, with regard to the different materials used (laterite, sandstone and bricks) and the period of construction ${ }^{13}$. The gross visual assessment combined with the results from Fourier transform infrared microscopy suggested that no mortar could have been used to join the bricks (from the absence of calcite) in Phnom Bakheng, and that just rubbing of the bricks together helped them to bond ${ }^{13}$. In the present study, even though the absence of lime was confirmed from XRD results as in the case of Phnom Bakheng, the presence of a thin layer of binding material was observed from the SEM images taken at the interface (Figures 7, 9 and 10).

\section{Test of compatibility between historic and new bricks}

Compatibility between the historic and new bricks was examined by analysis of the pore structure of the bricks and comparing the physico-mechanical properties of the two different brick types.

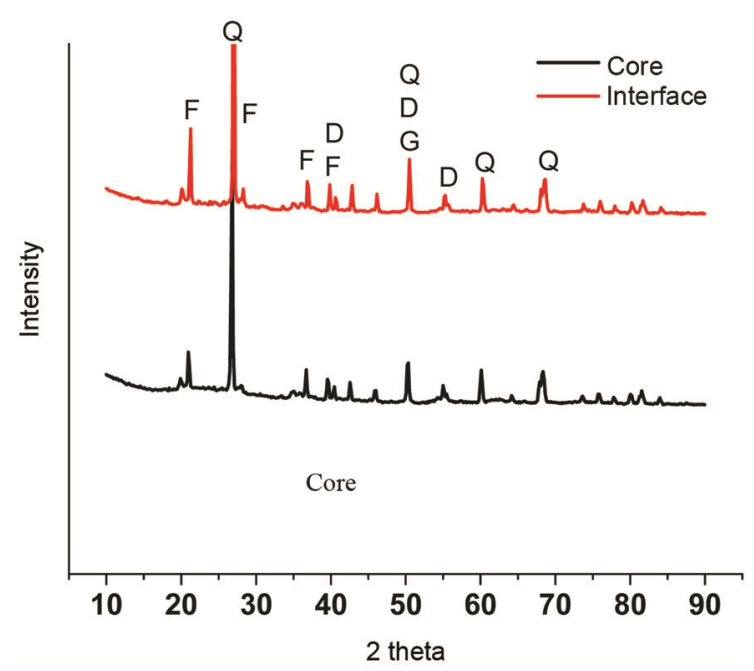

Figure 8. Diffractograms for the samples collected from historic bricks. Q, Quartz; F, Feldspar; D, Diopside; G, Gehlenite.

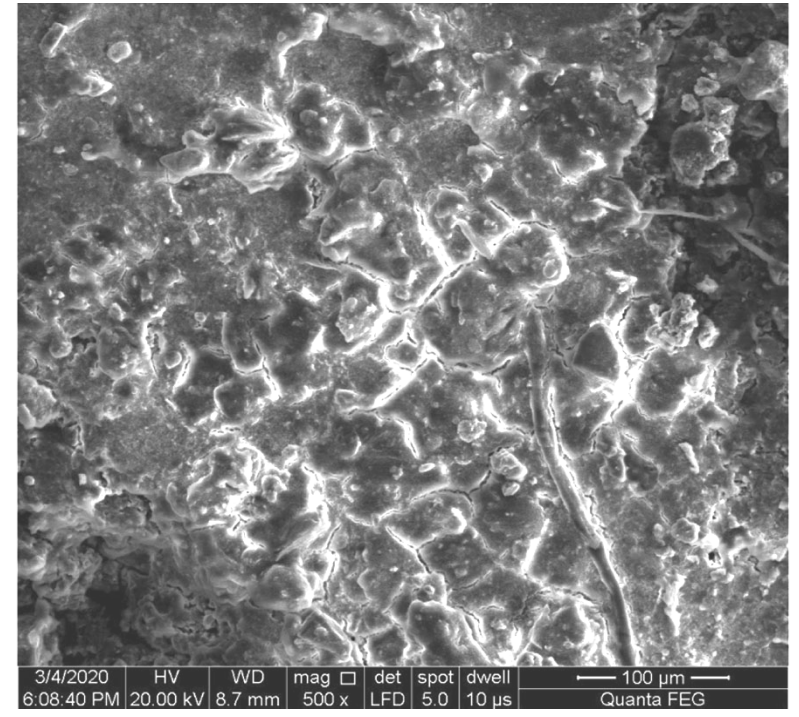

Figure 9. SEM image showing the presence of a binder layer at the interface between two bricks. 

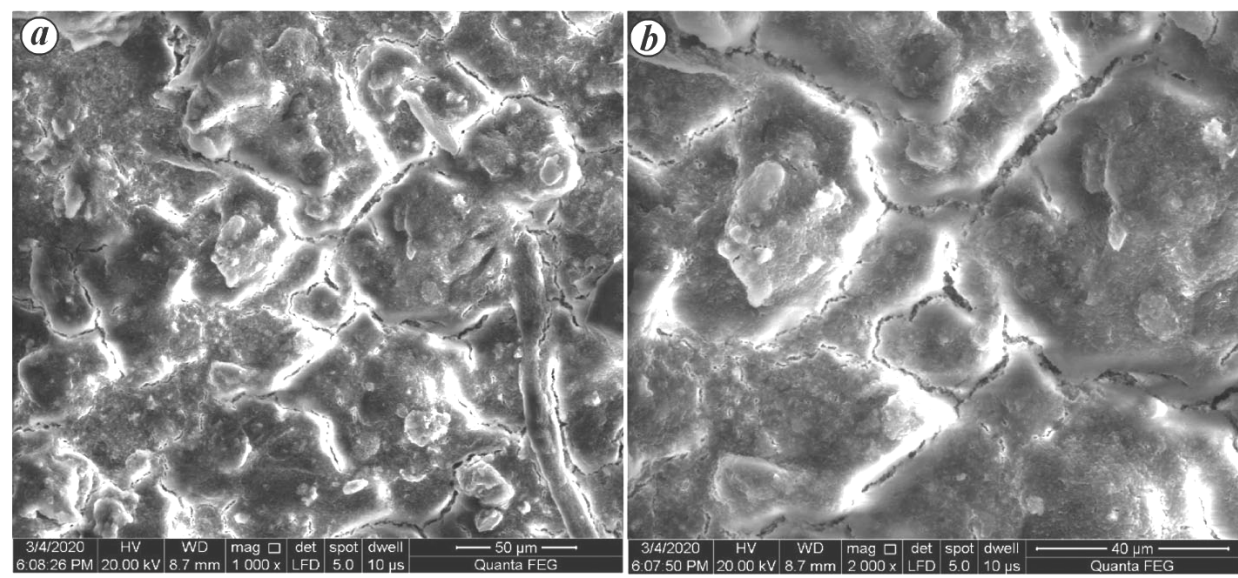

Figure $10 \boldsymbol{a}, \boldsymbol{b}$. Magnified views of the cracked layer of the binder at the interface. (a) At 1000X and (b) At 2000X.

(a)

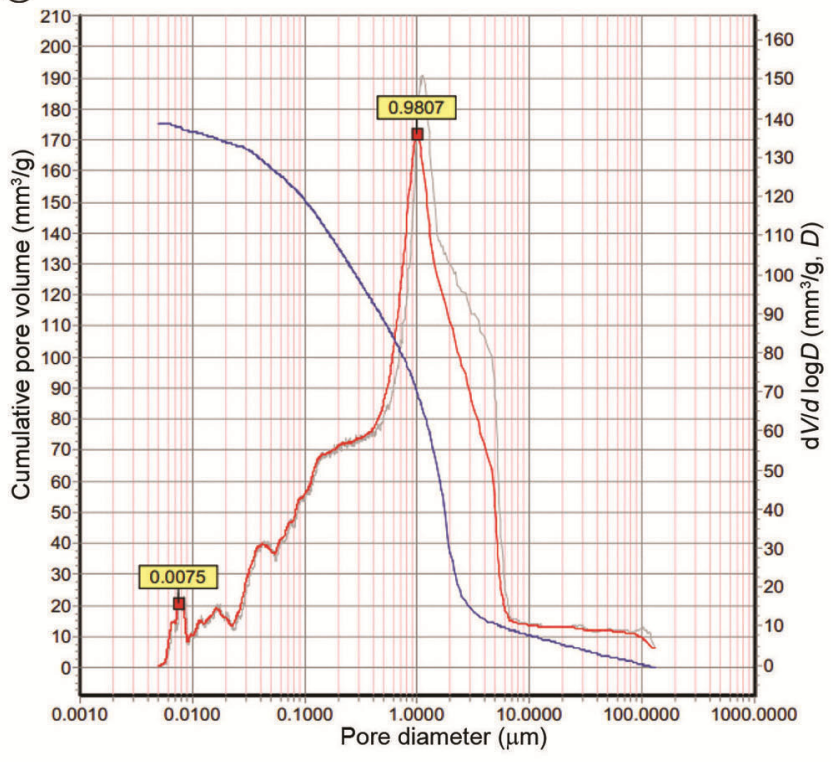

(b)

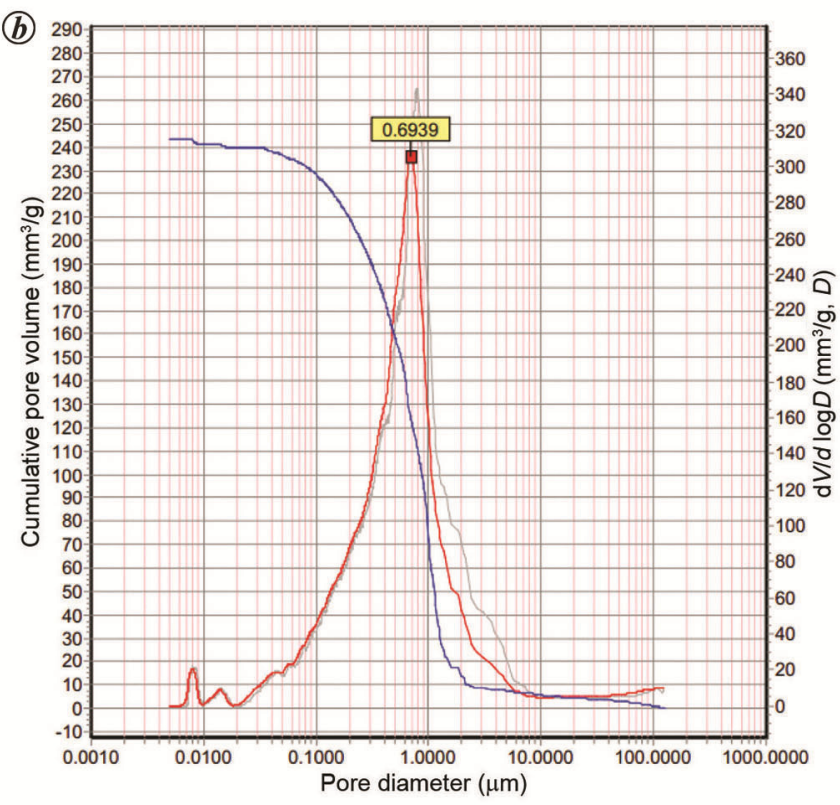

Figure 11. $\boldsymbol{a}$, Intrusion curves for the existing (historic) brick sample. $\boldsymbol{b}$, Intrusion curves for the new brick sample.

Study of porosity and pore-size distribution: Compatibility between the original ancient masonry unit and the newly introduced replacement unit plays a major role in determining their behaviour with respect to durability ${ }^{14}$. Porosity and pore structure are the most significant parameters in a material that affect its durability ${ }^{14}$. Porosity controls the ingress and transport of liquids/water into the system, which further leads to various deterioration mechanisms. Here, MIP was used to study and compare the pore parameters of the existing and newly manufactured bricks.

The data obtained from MIP on the amount of mercury intruded with pressure were used to obtain cumulative and differential intrusion curves. Pore parameters such as total porosity, total intruded volume, critical pore diameter and threshold pore diameter were the major deliver- ables from the experiment. Critical pore size is the pore diameter that corresponds to the highest frequency of pore size, and is obtained as the peak in the differential intrusion curve; threshold pore size is the minimum continuous pore diameter, after which a sudden influx of mercury can be seen in the cumulative intrusion curve. Systems that have finer pore size are expected to have lower values for both these parameters. Figure $11 a$ shows the intrusion curves for the historic brick sample and Figure $11 b$ shows the same for the new sample. The blue curve shows the cumulative volume intrusion and the red curve shows the differential intrusion in the figures. The peaks of the differential intrusion curves are also marked, which are the critical pore sizes. In the case of the historic sample, the critical pore size (which indicates the most common pore size in the system) was 


\section{RESEARCH ARTICLES}

$0.98 \mu \mathrm{m}$, while that for the new sample was $0.69 \mu \mathrm{m}$. Both values are less than $1 \mu \mathrm{m}$, which will thus result in similar durability properties ${ }^{14}$. There was a small increase in the threshold pore diameter of the historic sample compared to the new sample. This was also observed in the case of the critical pore size. However, the difference can possibly be due to the existing level of deterioration because of weathering in the historic samples.

Physico-mechanical properties: Table 1 shows results of the compressive strength tests conducted on the historic and new bricks. All the brick specimens, new and historic, showed classical compression failure with the sudden formation and propagation of vertical cracks. The average compressive strength from three new samples was found as $16.54 \mathrm{~N} / \mathrm{mm}^{2}$, whereas the compressive strength of the two available historic brick units was 4.76 and $6.63 \mathrm{~N} / \mathrm{mm}^{2}$ respectively. Clearly, the historic samples showed a much lower strength comparative to that of the new samples, which could be attributed to the presence of anomalies or weathering defects due to ageing within the bulk of the historic bricks. In addition, the inclusion of rice husk, which is evidenced from visual inspection and microscopic examination, could have an effect of reducing the compressive strength. As part of evaluating the quality of the new bricks, efflorescence test was conducted, which reveals the absence of any kind of salts within the bricks (neither from the mixing water, nor the raw materials). No patches of salt precipitation could be observed in the brick specimens during

Table 1. Compressive strength of the brick specimens

\begin{tabular}{lcc}
\hline Brick samples & Size $(\mathrm{mm})$ & $\begin{array}{c}\text { Compressive strength } \\
\left(\mathrm{N} / \mathrm{mm}^{2}\right)\end{array}$ \\
\hline New & \\
N1 & $150 \times 150 \times 50$ & 15.70 \\
N2 & $155 \times 150 \times 50$ & 16.80 \\
N3 & $155 \times 150 \times 50$ & 17.13 \\
Average & & 16.54 \\
Historic & & \\
H1 & $105 \times 110 \times 50$ & 6.63 \\
H2 & $110 \times 135 \times 50$ & 4.76 \\
\hline
\end{tabular}

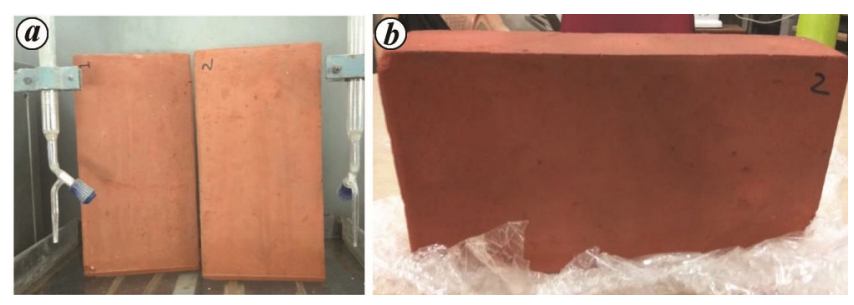

Figure 12. $\boldsymbol{a}$, Efflorescence test set-up and the samples before the test. $\boldsymbol{b}$, No salt precipitation was noticed on the brick surfaces during the test. and after seven days of partial immersion in water. Figure 12 shows images of a typical specimen of the new bricks just before and after the efflorescence test.

Water absorption (\%) was calculated for the new and the historic bricks after removing the possible binder interface layer between two bricks. Three replicates were tested for the new and historic bricks, and the values were found to be comparable. New bricks showed a water absorption of $20.08 \%$ with a standard deviation of $1.1 \%$, whereas the historic bricks showed average water absorption of $19.35 \%$ with a standard deviation of $2.78 \%$.

\section{Summary and conclusion}

The present study deployed micro-analytical characterization tools in addition to physical-mechanical properties to address the following aspects: (i) Characteristics of the historic bricks used in the brick gallery of the southern quadrangle of Vat Phou World Heritage Site of Lao PDR. (ii) Nature of the binder used in the brick masonrymortar joint. (iii) Compatibility between historic bricks and the newly sourced samples.

Visual observation showed a non-uniform spread of black powdery layer in the bricks which is soot due to the incomplete burning of organic matter. This was further examined through SEM imaging, which showed the presence of rice husk abundantly in the brick matrix of the historic sample, indicating deliberate inclusions of rice husk during the manufacture.

The nature of the binder used was studied with the help of mineral identification (by XRD) at the joint of the bricks and SEM imaging on samples collected from the interface. XRD and SEM studies on the joint interface between two historic bricks suggested that no lime-based binders were used in the construction. SEM imaging also confirmed the presence of a thin film of binder/coating at the joining interface between the two bricks. As no specific crystalline materials were identified at this location (interface) through XRD, it indicates the use of a plant extract as natural resin. The applied binder interface had cracks on observing through SEM imaging that represent weathering effects.

The compatibility between the historic and new bricks was analysed by comparing the pore structure using MIP and water absorption tests. The water absorption percentage estimated through the $24 \mathrm{~h}$ water absorption test also showed that the historic and new bricks had comparable water absorption. The pore structure and total porosity studied using MIP were found to be similar for both the historic and the new bricks, which indicated similar durability performance by both. The newly manufactured brick samples were thus found satisfactorily compatible with the historic bricks. From the limited number of samples available, the compressive strength of the new brick samples from a flat-wise compression test was almost 
three times greater than the historic brick samples. The lower strength of the historic bricks could be attributed to the presence of rice husk detected from the microanalytical studies and weathering over time. However, the greater strength of the new brick samples will not have negative implications for use in the restoration of the brick gallery. Strength of the bricks should not adversely affect conservation work as the level of compressive stresses will be rather low, given that it is a single-storey structure with no significant roof loads.

Conflicts of interest: None.

1. Santoni, M. et al., Excavations at Champasak and Wat Phu (southern Laos). South-East Asian Archaeology (eds Ciarla, R. and Rispoli, F.), 1992, Roma, 1997, pp. 233-263.

2. Pichard, P., La conservation des monuments de Vat Phu: bilan et perspectives, BEFEO, 2013, pp. 315-330.

3. Mission Report, Joint reactive monitoring mission to the Vat Phou and associated ancient settlements within the Champasak Cultural Landscape, World Heritage property, Lao People's Democratic Republic, 17-21 February 2015.

4. Freeman, M., A Guide to Khmer Temples in Thailand and Laos, Weatherhill, 1996, ISBN 0-8348-0450-6.

5. World Heritage Centre, UNESCO World Heritage, Vat Phou and associated ancient settlements within the Champasak cultural landscape. State of Conservation reports (2003-19); whc.unesco. org.

6. Meskell, L., UNESCO's World Heritage Convention at 40: challenging the economic and political order of international heritage conservation. Curr. Anthropol., 2013, 54(4), 483-494.

7. Hitchcock, M. and Harrison, D., The Politics of World Heritage, Cromwell Press, Great Britain, 2005.
8. ICOMOS Charter-Principles for the analysis, conservation and structural restoration of architectural heritage, International Council on Monuments and Sites, Paris, France, 2003.

9. ISCARSAH - Recommendations for the analysis, conservation and structural restoration of architectural heritage, 2003.

10. Manohar, S., Santhanam, M. and Chockalingam, N., Performance and microstructure of bricks with protective coatings subjected to salt weathering. Const. Build. Mater., 2019, 226, 94-105; https:// doi.org/10.1016/j.conbuildmat.2019.07.180.

11. Manohar, S., Bala, K., Santhanam, M. and Menon, A., Characteristics and deterioration mechanisms in coral stones used in a historical monument in a saline environment. Const. Build. Mater., 2020, 241, 118102, ISSN 0950-0618; https://doi.org/ 10.1016/j.conbuildmat.2020.118102.

12. Binda, L., Condoleo, P., Cucarzi, M., Vinh, L. T., Pichard, P. and Kính H. D., In Proceedings of 5th International Conference on Structural Analysis of Historical Constructions (eds Lourenco, P. R., Modena, C. and Agrawal, S.), Macmillan Advanced Research Series, Macmillan Ltd, New Delhi, 2006.

13. Report on Phnom Bakheng Brick Shrine Conservation and Stabilization Workshop, World Monuments Fund, New York, USA, 2010

14. Manohar, S., A study on characterisation, deterioration mechanisms and protection of bricks and stones in historic structures, Ph D dessertation, IIT Madras, Chennai, 2020.

ACKNOWLEDGEMENTS. We thank the Heritage Department, Ministry of Information, Culture and Tourism of Lao PDR and the Vat Phou team of Archaeological Survey of India (ASI) led by Mr K. J. Lucka, ASAE, under the India-Laos Cooperation Project and for the samples provided for the study.

Received 12 June 2020; accepted 24 July 2020

doi: $10.18520 / \mathrm{cs} / \mathrm{v} 119 / \mathrm{i} 8 / 1300-1307$ 